\title{
Avaliação do comportamento reológico de pastas de cimento com adição de óxido de grafeno
}

\author{
Evaluation of the rheological behavior of \\ cement pastes with addition of graphene oxide
}

Ricardo Augusto dos Santos Horta ${ }^{1}$, Júlia Ferreira Murta ${ }^{1}$,
Júnia Nunes de Paula ${ }^{1}$, José Márcio Fonseca Calixto

\footnotetext{
${ }^{1}$ Programa de Pós-Graduação em Engenharia Civil do Centro Federal de Educação Tecnológica de Minas Gerais CEFET-MG, Av. Amazonas, 7675 - Nova Gameleira, CEP 30510-000, Belo Horizonte, Minas Gerais, Brasil. e-mail: ricardocivi192@gmail.com,jufmurta@gmail.com,juniapaula@cefetmg.br

${ }^{2}$ Programa de Pós- Graduação em Materiais e Construção Civil da Universidade Federal de Minas Gerais - UFMG, Av. Presidente Antônio Carlos, 6627 - Pampulha, CEP 31270-901 Belo Horizonte, Minas Gerais, Brasil.

e-mail: calixto@ufmg.br
}

\begin{abstract}
RESUMO
A adição de óxido de grafeno (OG) em materiais cimentícios permite a obtenção de compósitos mais resistentes e duráveis, com menor carga de poluentes associada à sua produção. Pesquisas anteriores demonstraram que a adição de nanomateriais à pasta de cimento pode provocar o aumento nos parâmetros reológicos de viscosidade e limite de escoamento. Este estudo teve como objetivo investigar as alterações no comportamento reológico de pastas de cimento devido à adição de OG. De forma a cumprir este objetivo, foram realizados testes com OG produzido e patenteado no CTNano/UFMG (Centro de Tecnologia em Nanomateriais e Grafeno da Universidade Federal de Minas Gerais) nos teores de 0,03\% e 0,05\%, sobre pastas de cimento de classes CP-III e CP-V. Foram utilizados dois métodos de análise, o mini-slump e a reometria rotacional de fluxo. No ensaio de mini-slump, foram obtidas reduções no raio de espalhamento de 42,94\% (CP-III) e de 23,34\% (CP-V) em relação às amostras de referência, considerando a adição de 0,05\%OG. Para este mesmo percentual de adição e utilizando o reômetro, foram obtidos aumentos na viscosidade de $125,49 \%$ (CP-III) e $31,51 \%$ (CP-V) e aumentos de $82,24 \%$ (CP-III) e 38,87\% (CP-V) no limite de escoamento. Ambas as técnicas utilizadas se mostraram eficientes na determinação da influência da adição do OG sobre a reologia das pastas de cimento, e apontaram para um aumento na viscosidade da pasta à medida que uma maior quantidade de $\mathrm{OG}$ é incorporada à mistura. A diferença principal entre as técnicas apresentadas está na qualidade dos resultados obtidos. Enquanto a reometria rotacional de fluxo é um método mais sofisticado e produz um relatório de resultados mais completo e preciso, a técnica de mini-slump tem como vantagem permitir a visualização dos efeitos das adições sobre a fluidez e a consistência das pastas de cimento.
\end{abstract}

Palavras-chave: Óxido de grafeno. Nanomateriais. Comportamento reológico. Compósitos cimentícios.

\begin{abstract}
ABTRACT
The addition of graphene oxide (GO) in cementitious materials makes it possible to obtain more resistant and durable composites, with lower pollutant load associated with their production. Previous research has shown that the addition of nanomaterials to the cement paste can cause a reduction in the rheological parameters of viscosity and yield stress. This study aimed to investigate changes in the rheological behavior of cement pastes due to GO addition. In order to fulfill this objective, tests were carried out with GO produced and patented at CTNano / UFMG (Technology Center for Nanomaterials and Graphene at the Federal University of Minas Gerais) in the contents of $0.03 \%$ and $0.05 \%$, on cement pastes classes CP-III and CP-V. Two methods of analysis were used, the mini-slump and the rotational flow rheometry. In the mini-slump test,
\end{abstract}


reductions in the spreading radius of $42,94 \%(\mathrm{CP}-\mathrm{III})$ and $23,34 \%(\mathrm{CP}-\mathrm{V})$ were obtained in relation to the reference sample, considering an addition of $0.05 \% \mathrm{GO}$. For this same percentage of addition and using the rheometer, increases of $125,49 \%$ (CP-III) and $31,51 \%$ (CP-V) in viscosity were obtained, as well as increases of $82,24 \%$ (CP-III) and $38,87 \%(\mathrm{CP}-\mathrm{V})$ in the yield stress. Both techniques used proved to be efficient in determining the influence of the addition of GO on the rheology of cement pastes, and pointed to an increase in the viscosity of the paste as a greater amount of GO is incorporated into the mixture. The main difference between the techniques presented is in the quality of the results obtained. While rotational flow rheometry is a more sophisticated method and produces a more complete and accurate results report, the mini-slump technique has the advantage of allowing the visualization of the effects of additions on the fluidity and consistency of cement pastes.

Keywords: Graphene oxide. Nanomaterials. Rheological behaviour. Cement composites.

\section{INTRODUÇÃO}

Nos últimos anos tem havido um interesse crescente da indústria da construção e de órgãos do governo ligados à infraestrutura no desenvolvimento de materiais mais resistentes e de maior durabilidade, capazes de reduzir o impacto ambiental das edificações.

Estima-se que a construção civil seja responsável pelo consumo de 40-75\% de toda a matéria prima produzida no planeta, além de contribuir com 40-50\% de todas as emissões globais de gases de efeito estufa e chuva ácida na atmosfera. Além disso, o ciclo de vida das edificações representa cerca de $40 \%$ da demanda global de energia. Ao longo dos anos, estes impactos resultaram em alterações no meio ambiente e no clima, a ponto de a qualidade de vida no planeta estar ameaçada. Eventos climáticos extremos como ondas de calor, tempestades e inundações têm aumentado de intensidade e atingido os grandes centros urbanos com bastante frequência. Frente à emergência da crise ambiental, o setor da construção civil é convocado a adequar seus processos produtivos a este novo paradigma [1].

Materiais de reforço como barras de aço, fibras de aço, fibras de carbono, fibras de vidro e polímeros foram extensivamente aplicados em concretos nos últimos anos. Embora estes materiais possam melhorar bastante a resistência do concreto como um todo, a alta fragilidade e fraturas associadas a esta propriedade ainda ocorrem, resultando na baixa durabilidade das estruturas [2]. Os nanomateriais (nano sílica, nanotubos de carbono e derivados do grafeno) podem fornecer uma solução melhor do que as fibras tradicionais por meio do reforço na nano-escala e disponibilização de uma área de superfície específica muito maior para interação na matriz de cimento [3].

Dentre os nanomateriais, o óxido de grafeno (OG) apresenta um enorme potencial para aplicação nos compósitos cimentícios. O OG é tipicamente produzido a partir da oxidação do grafite, esfoliação e purificação em um processo conhecido como método de Hummers [4]. O OG consiste em uma estrutura plana de átomos de carbono interligados em formato hexagonal, com orbitais hibridizados $\operatorname{sp}^{2}$ e $\operatorname{sp}^{3}$ [5]. Segundo LU et al. [6], o OG é um material hidrofílico devido à presença de grupos funcionais de oxigênio no plano basal e bordas de sua estrutura molecular, como pode ser visto na Figura 1.

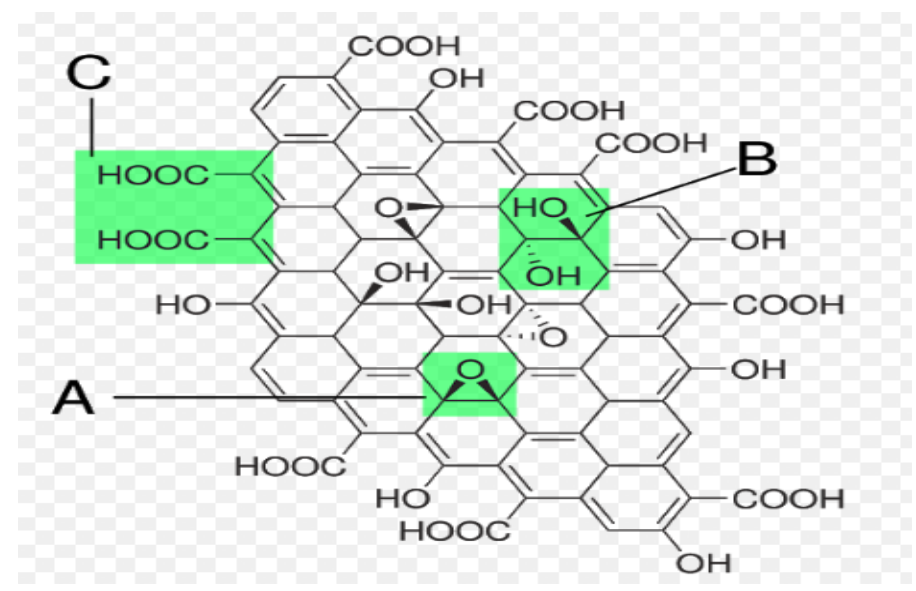

Figura 1: Estrutura molecular do óxido de grafeno (A: Grupo epoxílico, B: Grupo hidroxílico, C: Grupo carboxílico).

Como uma nova classe de nanomaterial em escala bidimensional, o OG tem recebido grande atenção em vários campos de aplicação na área de engenharia civil, devido à sua elevada superfície específica, boa dispersão em água, elevada condutividade térmica e elétrica, elevado módulo de elasticidade, além de 
elevada resistência à tração [1, 7-9].

A incorporação do óxido de grafeno aos materiais cimentícios ajuda a promover a sustentabilidade na construção civil com o seguinte potencial de contribuições, segundo YANG et al. [1]: (i) aumento da capacidade de carga das estruturas em concreto, principalmente a resistência à tração, reduzindo a fragilidade destes materiais; (ii) aumento da durabilidade das estruturas em concreto, por meio da redução da porosidade e da permeabilidade da matriz cimentícia; (iii) possibilidade de redução do consumo de cimento na fase de produção de estruturas em concreto; (iv) promoção de arquiteturas com design inovador, a partir da elaboração de estruturas com menor peso próprio; (v) alta resistência inicial das estruturas, podendo reduzir o tempo dos ciclos construtivos.

Contudo, pesquisas anteriores demonstraram que adição de nanomateriais à pasta de cimento pode provocar a redução nos parâmetros reológicos tais como viscosidade e limite de escoamento. Isso ocorre devido à elevada superfície específica dos nanomateriais, que requer grande quantidade de água para molhar a sua superfície reduzindo assim o conteúdo de água disponível para a lubrificação. Além disso, os nanomateriais possuem tendência a aglomerar, devido às interações de van der Waals existentes entre as moléculas, o que, quando ocorre em larga escala, resulta na menor fluidez dos materiais cimentícios $[4,10$, $11]$.

Este trabalho objetivou avaliar o comportamento reológico de pastas de cimento produzidas com adição de diferentes teores de óxido de grafeno sem o uso de aditivos plastificantes, para que fosse possível verificar somente a influência do OG. Efetuou-se a adição de uma solução de óxido de grafeno produzida e patenteada no CTNano/UFMG ${ }^{1}$ em pastas de cimento Portland. Foram utilizados, neste trabalho, dois métodos de análise: o mini-slump (ensaio monoponto) e a reometria rotacional de fluxo (ensaio multiponto).

\section{MATERIAIS E MÉTODO}

\subsection{Materiais}

\subsubsection{Cimento Portland}

Foram utilizados, neste trabalho, dois tipos de cimento: CP-III-RS-40 (cimento com 35-70 \% de adição de escória de alto forno) e CP-V-ARI (cimento puro de alta resistência inicial). O cimento CP-III foi escolhido com o objetivo de investigar o efeito da adição do OG em um cimento com adições e o potencial de utilização do OG nas construções in loco. A justificativa pela escolha do cimento $\mathrm{CP}-\mathrm{V}$ é verificar a influência da adição do OG em um cimento sem adições e a aplicabilidade do óxido de grafeno para a indústria de pré-fabricados de concreto.

Os ensaios físicos e químicos para cada tipo de cimento foram realizados na própria fábrica e os relatórios gerados foram disponibilizados pelo fabricante. A Tabela 1 reúne as principais informações referentes aos ensaios realizados e limites normativos da ABNT NBR 16.697/2018 - Cimento Portland Requisitos [12].

Tabela 1: Resultados dos ensaios físicos e químicos dos cimentos utilizados e limites normativos.

\begin{tabular}{ccccc}
\hline \multirow{2}{*}{ Parâmetros } & \multicolumn{2}{c}{ CP-III-RS-40 } & \multicolumn{2}{c}{ CP-V-ARI } \\
\cline { 2 - 5 } & $\begin{array}{c}\text { Cimento } \\
\text { utilizado }\end{array}$ & $\begin{array}{c}\text { Limites NBR } \\
\mathbf{1 6 . 6 9 7 / 2 0 1 8}\end{array}$ & $\begin{array}{c}\text { Cimento } \\
\text { utilizado }\end{array}$ & $\begin{array}{c}\text { Limites NBR } \\
\mathbf{1 6 . 6 9 7 / 2 0 1 8}\end{array}$ \\
\hline Data de ensacamento & $13 / 08 / 2016$ & - & $28 / 03 / 2018$ & - \\
\hline Massa específica $\left(\mathrm{g} / \mathrm{cm}^{3}\right)$ & 3,03 & - & 3,13 & - \\
\hline Finura Blaine $\left(\mathrm{cm}^{2} / \mathrm{g}\right)$ & 4642 & - & 5112 & $\geq 3000$ \\
\hline $\begin{array}{c}\text { Retido na peneira }{ }^{\circ} \text { 200 } \\
(\# 75 \mu \mathrm{m})(\%)\end{array}$ & 0,467 & $\leq 8,0$ & 2,0 & $\leq 6,0$ \\
\hline Início de pega $(\mathrm{min})$ & 180 & $\geq 60$ & 120 & $\geq 60$ \\
\hline Fim de pega $(\mathrm{min})$ & 250 & $\leq 720$ & 180 & $\leq 600$ \\
\hline Água de consistência $(\%)$ & 29,38 & - & 31,20 & - \\
\hline $\mathrm{SO}_{3}(\%)$ & 2,38 & $\leq 4,5$ & 3,82 & $\leq 4,5$ \\
\hline $\mathrm{MgO}(\%)$ & 3,43 & - & 2,7 & - \\
\hline $\mathrm{SiO}_{2}(\%)$ & 24,09 & - & 19,6 & \\
\hline
\end{tabular}

\footnotetext{
${ }^{1}$ CTNano/UFMG: Centro de Tecnologia em Nanomateriais e Grafeno da UFMG (Universidade Federal de Minas Gerais).
} 


\begin{tabular}{ccccc}
\hline $\mathrm{Al}_{2} \mathrm{O}_{3}(\%)$ & 6,36 & - & 4,6 & - \\
\hline $\mathrm{Fe}_{2} \mathrm{O}_{3}(\%)$ & 3,30 & - & 2,3 & - \\
\hline $\mathrm{CaO}(\%)$ & 54,81 & - & 61,4 & - \\
\hline $\mathrm{Na}_{2} \mathrm{O}(\%)$ & 0,14 & - & 0,08 & - \\
\hline $\mathrm{K}_{2} \mathrm{O}(\%)$ & 0,67 & - & 0,8 & $\leq 6,5$ \\
\hline Perda ao fogo $(\%)$ & 3,47 & $\leq 6,5$ & 3,89 & $\leq 3,5$ \\
\hline Resíduo insolúvel (\%) & 1,40 & $\leq 5,0$ & não informado & \\
\hline
\end{tabular}

Como se pode observar, os cimentos utilizados no programa experimental deste trabalho atendem aos requisitos técnicos estabelecidos pela norma ABNT NBR 16.697/2018.

\subsubsection{Solução de óxido de grafeno}

O óxido de grafeno utilizado neste trabalho foi sintetizado a partir do grafite, em um método conforme a patente BR 102016005632-2 A2, de propriedade do CTNano/UFMG. Este método envolve, essencialmente, três etapas: oxidação, esfoliação e purificação. Na oxidação, o grafite, material composto por várias folhas de grafeno interligadas por meio de forças de Van der Waals, é submetido à oxidação por meio de agentes químicos oxidantes em meio ácido (utilizam-se $\mathrm{KMnO} 4$ e H2SO4). Neste processo, grupos funcionais de oxigênio como hidroxila $(-\mathrm{OH})$, carboxila $(-\mathrm{COOH})$ e carbonila $(\mathrm{C}=\mathrm{O})$ são inseridos na estrutura molecular do grafite convertendo-o em óxido de grafite. A inserção destes grupos funcionais de oxigênio, processo denominado funcionalização, provoca o distanciamento entre as folhas de grafeno e consequentemente enfraquece as ligações intermoleculares, tornando o óxido de grafite um material hidrofílico (com boa dispersão em meio aquoso). Em seguida, a solução de óxido de grafite é submetida à ultrassonificação para a obtenção de camadas singulares dispersas, em um processo denominado esfoliação, dando origem à solução de óxido de grafeno. O OG permanece disperso em solução aquosa pelo tempo médio de 90 dias. Por fim, utiliza-se água destilada e filtragem à vácuo para a remoção dos íons remanescentes do ácido e dos agentes químicos oxidantes, em um processo conhecido como purificação. O método descrito é representado na Figura 2.

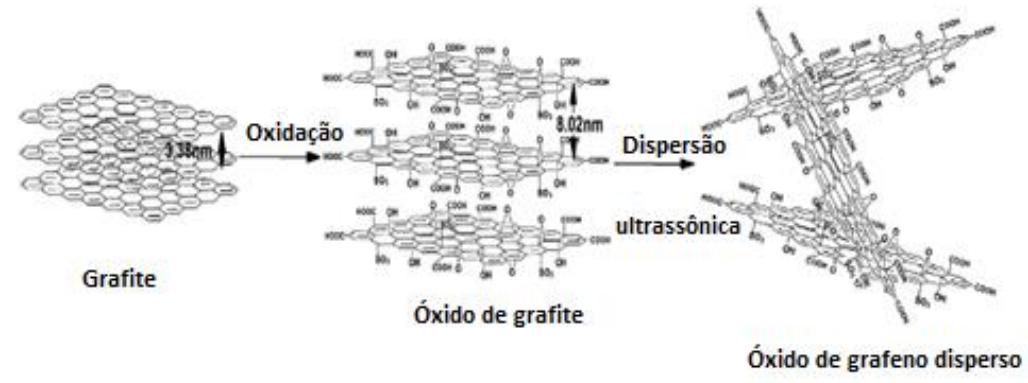

Figura 2: Síntese da solução de óxido de grafeno, segundo LV et al. [13].

A solução de OG obtida apresenta estruturas com 1 a 7 folhas de espessura (dimensão lateral de $5 \mu \mathrm{m}$ ), na concentração de 5,0 g/L. O grau de oxidação é de $40 \%$ em massa.

A equipe técnica do CTNano/UFMG realizou ensaios de caracterização sobre o óxido de grafeno fornecido para a realização desta pesquisa. Os ensaios de caracterização consistiram em análise termogravimétrica (TGA) e microscopia eletrônica de transmissão (MET). No ensaio de TGA (Figura 3), ficou constatado que a amostra de óxido de grafeno sólido perde até $40 \%$ de sua massa quando aquecida a uma temperatura de $400^{\circ} \mathrm{C}$. Na temperatura de $543^{\circ} \mathrm{C}$, a amostra de $\mathrm{OG}$ passa quase que em sua totalidade para o estado gasoso. A razão de aquecimento da amostra foi de $5^{\circ} \mathrm{C} / \mathrm{min}$.

Para a realização do ensaio de MET (Figura 4), foram depositadas amostras da solução de OG em grades de cobre/carbono. Por meio deste ensaio, foi possível observar, sob as escalas de magnitude de $5 \mu \mathrm{m}$ (Figura 4-a) e 10nm (Figura 4-b), a estrutura bidimensional das folhas de óxido de grafeno. Na Figura 4-a observam-se faixas na cor preta/cinza, que são as folhas de OG interligadas. O que aparentam ser "bolhas" são as grades de cobre/carbono. Na Figura 4-b podemos vemos a estrutura do OG e a região de fronteira com o auxílio de uma lente com maior poder de resolução. 


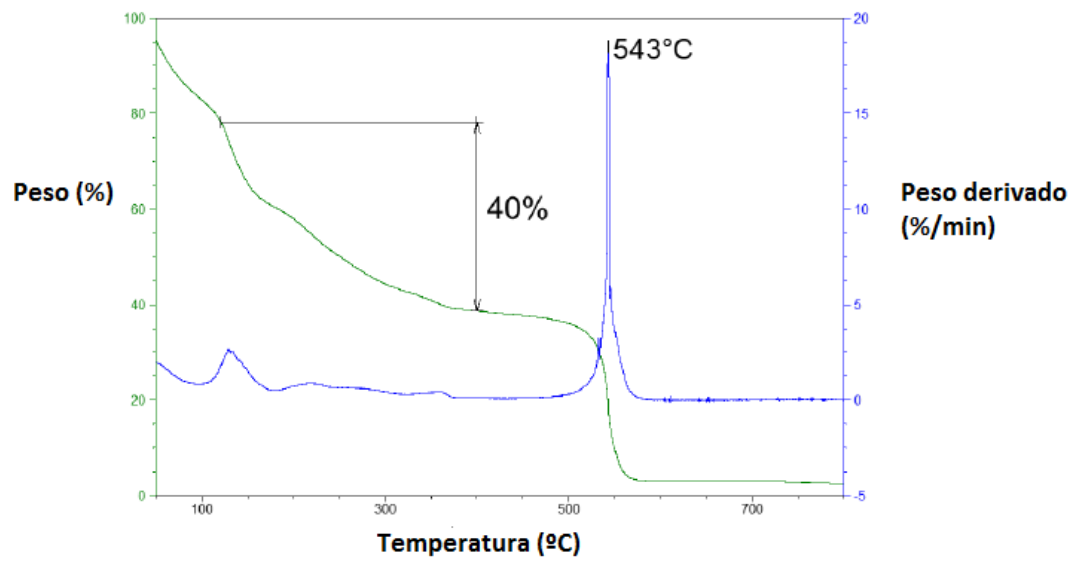

Figura 3: Análise termogravimétrica (TG) do OG sólido.
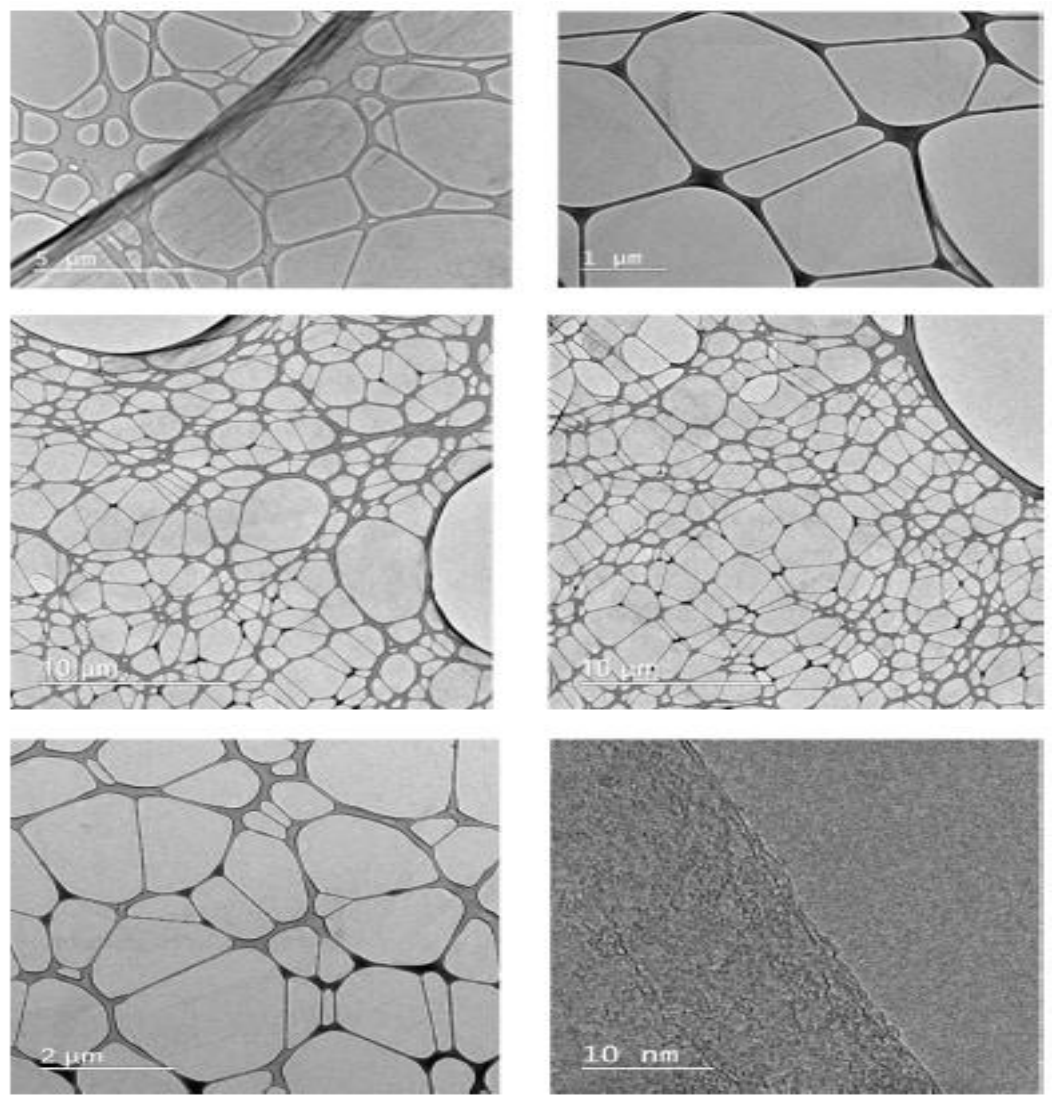

Figura 4: Microscopia eletrônica de transmissão (MET), obtida pela deposição da dispersão de OG em grades de cobre/carbono. Escalas de magnitude de $5 \mu \mathrm{m}$ (Figura 4-a) e 10nm (Figura 4-b).

\subsection{3. Água}

Foi utilizada água fornecida pela COPASA aos laboratórios do CTNano/UFMG para completar a água da solução de OG utilizada.

\subsection{Método}

\subsubsection{Produção das pastas de cimento}

Identificou-se, por meio de revisão bibliográfica, que os teores de adição de OG que conduzem aos melhores resultados de resistência à compressão e tração dos materiais cimentícios são de $0,03 \%$ e $0,05 \%$, conforme 
apresentado nos estudos realizados por LV et al. [2], PAN et al. [4], GONG et al. [10], LV et al. [13], WANG M. et al. [14] e WANG Q. et al. [15].

Com base nisto, foram preparadas pastas com cimento CP-III-RS-40 e CP-V-ARI com 3 teores distintos do nanomaterial: (i) referência (sem OG), (ii) acréscimo de OG na proporção de $0,03 \%$ da massa de cimento e (iii) acréscimo de OG na proporção de $0,05 \%$ da massa de cimento. Foi utilizada uma relação água/cimento fixa de 0,5 , valor escolhido com a finalidade única de se evitar o uso de aditivos plastificantes, minimizando assim o número de variáveis que podem influenciar no resultado final. A composição das pastas de cimento que foram submetidas aos ensaios de reologia é mostrada na Tabela 2.

Tabela 2: Composição das pastas de cimento utilizadas nos experimentos.

\begin{tabular}{cccc}
\hline Identificação & Cimento $(\mathbf{g})$ & Solução de OG 5,0g/L $(\mathbf{m L})$ & Água $(\mathbf{m L})$ \\
\hline CP-III-REF & 720 & 0 & 360 \\
\hline CP-III-0,03\%OG & 720 & 43,20 & 316,80 \\
\hline CP-III-0,05\%OG & 720 & 72 & 288 \\
\hline CP-V-REF & 720 & 0 & 360 \\
\hline CP-V-0,03\%OG & 720 & 43,20 & 316,80 \\
\hline CP-V-0,05\%OG & 720 & 72 & 288 \\
\hline
\end{tabular}

As pastas de cimento foram preparadas em uma cuba de inox com capacidade para $600 \mathrm{~mL}$ por meio de um misturador de palhetas, disponível no CTNano/UFMG. A ordem para colocação dos materiais seguiu a seguinte sequência: (i) adição de água; (ii) adição da solução de óxido de grafeno e (iii) adição do cimento. Na Figura 5 é mostrado o misturador de palhetas Chandler Engineering ${ }^{\mathrm{TM}}$ utilizado.

Figura 5: Misturador de palhetas Chandler Engineering ${ }^{\mathrm{TM}}$

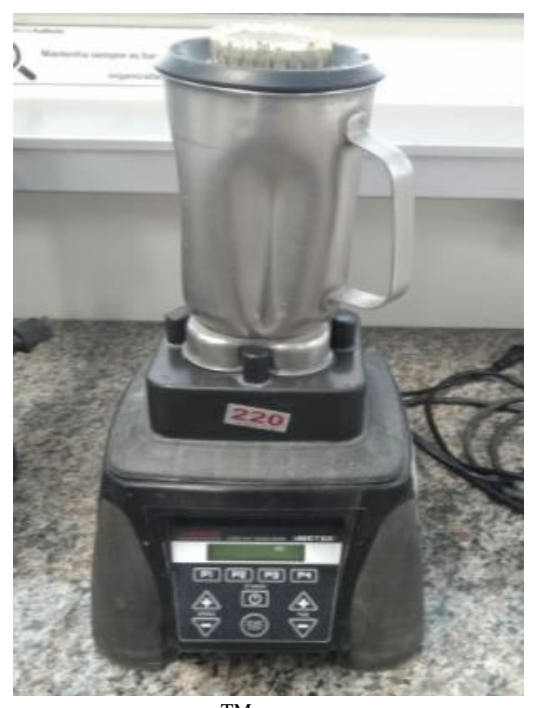

A programação da agitação mecânica consistiu em 2 ciclos de rotação a $5.000 \mathrm{rpm} \pm 200 \mathrm{rpm}$ por 30 segundos com uma mistura manual de 15 segundos durante o intervalo entre os ciclos. Esta energia de mistura foi definida com base nos estudos realizados por RAUCCI et al. [16], SOARES [17] e a partir de calibrações realizadas no Laboratório de Cimento do CTNano/UFMG. Tal procedimento foi definido pelo fato de proporcionar melhor mistura da pasta cimentícia e menor interferência no sistema de hidratação do cimento.

Após o preparo das pastas, foi realizada a sua homogeneização utilizando um consistômetro atmosférico (Figura 6), modelo 1200 da marca Chandler EngineeringTM. O equipamento é basicamente um recipiente com um banho de água no qual são alojados dois cilindros que giram a $150 \pm 15 \mathrm{rpm}$. Cada célula apresenta internamente uma palheta estacionária imersa na pasta de cimento, que por sua vez transmite o torque imposto pela pasta a uma mola acoplada a um dial, indicando a consistência da pasta. 


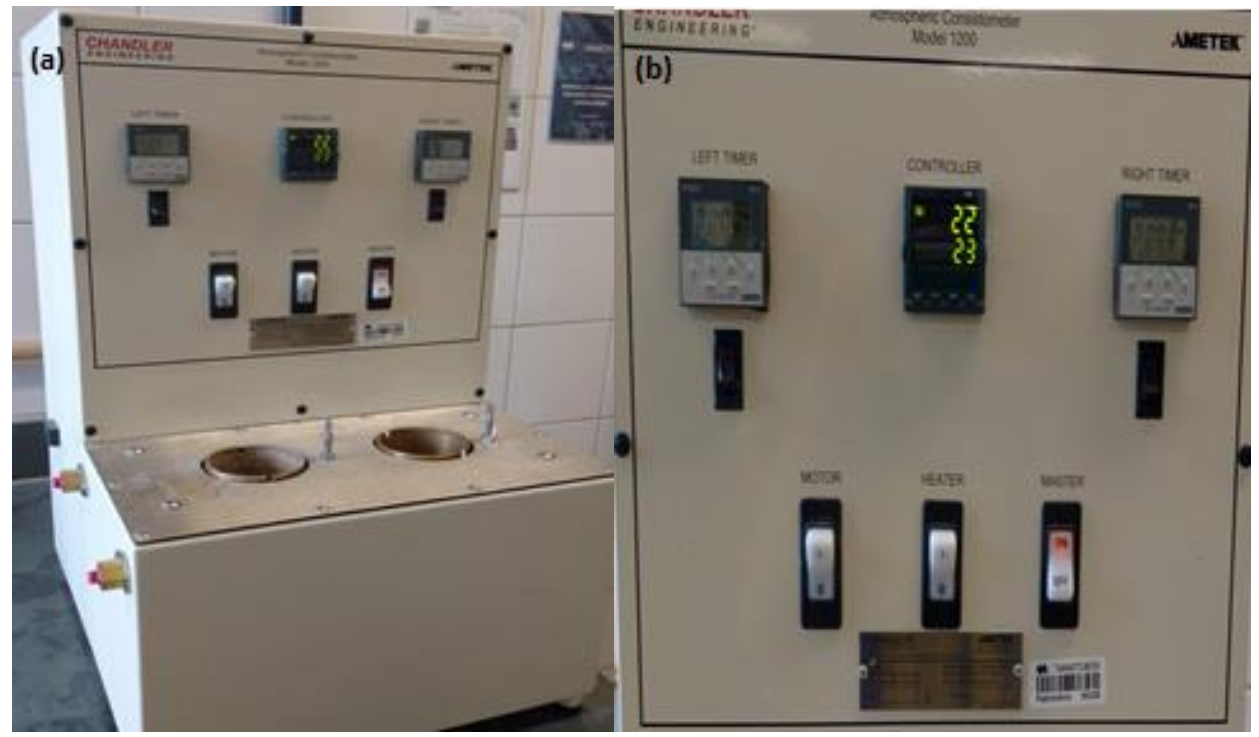

Figura 6: Consistômetro atmosférico utilizado na homogeneização das pastas: (a) Perfil do equipamento. (b) Painel de controle.

O procedimento de homogeneização das pastas foi realizado conforme PROCELAB [18]. Consistiu em verter as pastas de cimento recém-preparadas para o cilindro e condicioná-las por 20 minutos, sendo que a temperatura do banho manteve-se em $25{ }^{\circ} \mathrm{C} \pm 1{ }^{\circ} \mathrm{C}$. Após este período, a palheta é retirada e a pasta de cimento é agitada por mais 5 segundos com o auxílio de uma espátula. O período de 20 minutos de condicionamento no consistômetro foi definido de acordo com PROCELAB [18] e MAKAR et al. [19].

Segundo MAKAR et al. [19], as principais reações de hidratação do cimento Portland ocorrem principalmente pela formação dos compostos aluminato tricálcico $\left(\mathrm{C}_{3} \mathrm{~A}\right)$, silicato tricálcico $\left(\mathrm{C}_{3} \mathrm{~S}\right)$, aluminoferrato tetracálcico $\left(\mathrm{C}_{4} \mathrm{AF}\right)$ e silicato dicálcico $\left(\mathrm{C}_{2} \mathrm{~S}\right)$. No início do processo de hidratação (primeiro estágio), o $\mathrm{C}_{3} \mathrm{~A}$ reage instantaneamente com a água e o sulfato de cálcio do sistema, sendo esta uma reação altamente exotérmica e pouco controlada, com duração aproximada de 20 minutos. Após este intervalo de tempo a pasta de cimento inicia o estágio de dormência ou de indução, período em que a evolução do calor de hidratação é relativamente baixa e a consistência da pasta é mantida constante até o início da pega. É neste período em que devem ser realizados os ensaios de reologia e calor de hidratação das pastas de cimento.

\subsubsection{Ensaio de mini-slump}

O ensaio de mini-slump foi realizado após $30 \mathrm{~min}$ do início da mistura do cimento com a água e a solução de OG, sendo utilizado para avaliar a propagação do raio de espalhamento e a fluidez das pastas de cimento no estado fresco. Embora seja considerado um ensaio monoponto (aplicação de um único par de valores de tensão e taxa de cisalhamento), seus resultados são bem relevantes na ausência de métodos de ensaio mais sofisticados.

O método de ensaio de mini-slump ainda não é normatizado e o procedimento foi executado conforme RAUCCI et al [16], SOARES [17], KANTRO [20], PASHIAS et al. [21], CASTRO e LIBORIO [22] e ROUSSEL et al. [23],

Aproximadamente $80 \mathrm{ml}$ da pasta de cimento foram vertidos no mini-slump de Kantro, que por sua vez já estava posicionado sobre o centro da mesa de medição do ensaio (base de vidro sobre um papel milimetrado previamente demarcado). Em seguida, foram empregados dez golpes na pasta, com uma vareta de vidro, para evitar a formação de bolhas de ar dentro do cone. $\mathrm{O}$ excesso de pasta no topo do molde foi, então, removido. $\mathrm{O}$ molde foi levantado com velocidade adequada para assegurar uma mínima perturbação lateral e minimizar os efeitos inerciais. Após a completa parada da pasta, os raios de espalhamento foram anotados, em milímetros, nas seguintes direções: direita, esquerda, acima e abaixo. Por fim, foi determinado o raio médio de espalhamento das pastas. A execução do ensaio é apresentada na Figura 7, tendo sido realizadas cinco repetições para cada traço analisado. 


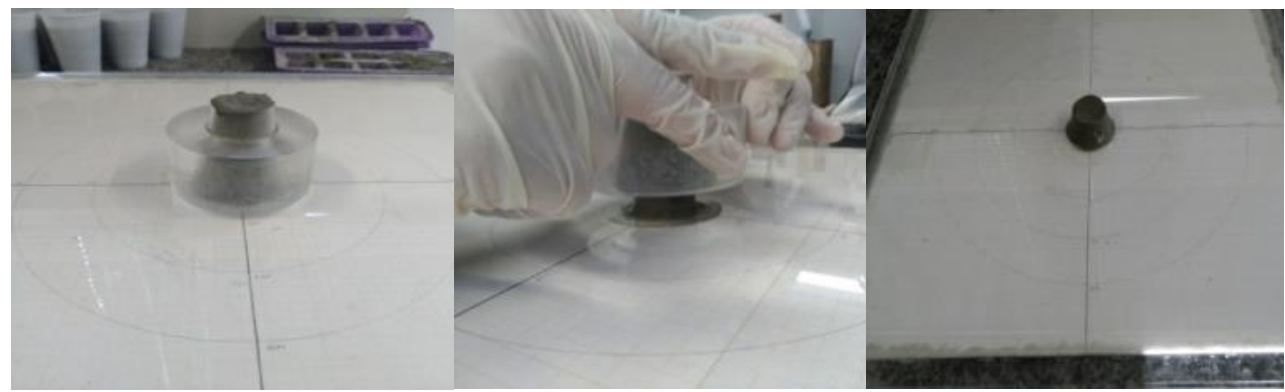

Figura 7: Execução do ensaio de mini-slump.

\subsubsection{Ensaio de reometria rotacional de fluxo (reômetro)}

O ensaio de reometria rotacional de fluxo foi realizado após $30 \mathrm{~min}$ do início da mistura do cimento com a água, e consistiu em submeter a pasta de cimento recém preparada a um movimento rotacional, variando a tensão de cisalhamento e a taxa de cisalhamento impostas pelo reômetro.

Durante o ensaio, o reômetro permanece conectado a um computador, que, com o auxílio do software RHEOTEST® RN4 Manager, obtém um conjunto de dados para analisar o comportamento reológico das amostras. Este software também foi responsável pelo controle do equipamento e pelas características do ensaio. Ele permitiu controlar a intensidade da taxa de cisalhamento aplicada, os tempos em que a taxa de cisalhamento levou para chegar a seus valores máximo (aceleração) e mínimo (desaceleração), bem como a quantidade de leituras realizadas e a duração total do ensaio.

A Figura 8 ilustra o reômetro utilizado nos experimentos. Este equipamento possui um cilindro interno, denominado spindle, que gira enquanto o cilindro externo (porta amostra) fica estático, conforme Figura 8a. O equipamento montado no momento do ensaio é mostrado na Figura 8b.
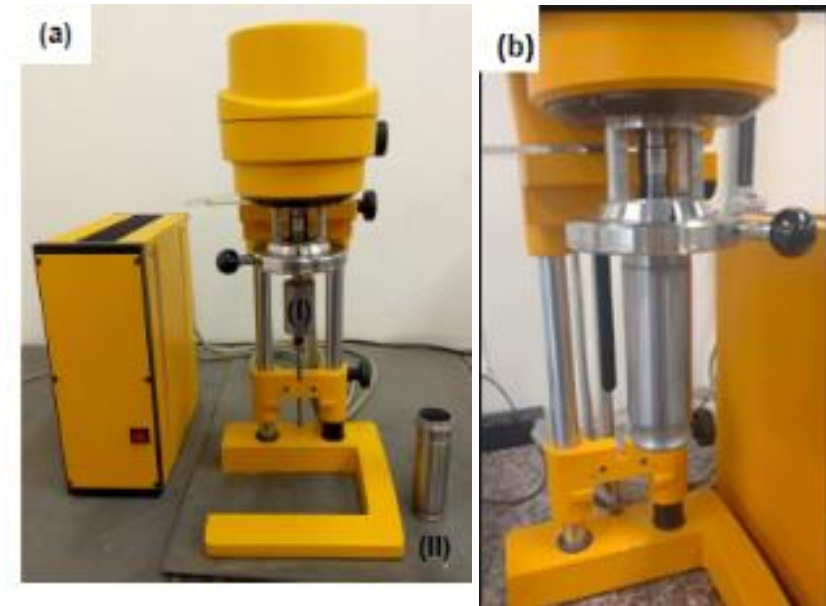

Figura 8: Rheotest Medingen GmbH, modelo RN 4.1, disponível no CTNano/UFMG: (a) Detalhes do equipamento - (I) spindle e (II) porta amostra. (b) Equipamento montado.

Aproximadamente $55 \mathrm{ml}$ da pasta de cimento foram vertidos no porta amostra, em seguida este foi fixado no suporte do equipamento, que por sua vez já estava com o spindle acoplado no rotor do reômetro. $\mathrm{O}$ spindle vaza a pasta de cimento, fazendo com que um espaço de cerca de $1,5 \mathrm{~mm}$ de largura entre a face externa do cilindro e o porta amostra seja preenchido com o fluido. $\mathrm{O}$ atrito intrínseco das camadas de pasta de cimento ocorre entre o porta amostra e o spindle. Os dados de ensaio são gravados quando o rotor do cilindro faz uma curva devido à sua conexão com a escala de medição.

Todos os ensaios reológicos foram realizados de forma padronizada para reduzir a influência do meio externo, no Laboratório de Cimento do CTNano/UFMG em Belo Horizonte. Visando minimizar a influência do ambiente, o ensaio foi realizado em sala climatizada com temperatura de $20^{\circ} \mathrm{C}\left( \pm 2{ }^{\circ} \mathrm{C}\right)$ e umidade relativa do ar de $30 \%( \pm 20 \%)$. Foram realizadas três repetições para cada traço.

Foram realizadas várias calibrações e estudos para determinação da melhor metodologia de ensaio para as pastas de cimento CPIII-40 RS e CPV-ARI. A metodologia escolhida foi programada em um ciclo de histerese composto por duas rampas, conforme a Figura 9. Na primeira rampa, conhecida como rampa de aceleração, foi aplicada uma taxa de cisalhamento crescente de 0 a $100 s^{-1}$ durante 120 segundos, a qual deu 
origem a curva de fluxo ascendente. Imediatamente depois, uma taxa de cisalhamento de desaceleração de 100 a $0 s^{-1}$ foi aplicada durante outros 120 segundos, dando origem à segunda rampa (curva de fluxo descendente). Foram coletados 60 pontos por rampa, ou seja, um ponto a cada 2 segundos. Assim, cada ciclo foi executado em quatro minutos, gerando um total de 120 pontos.

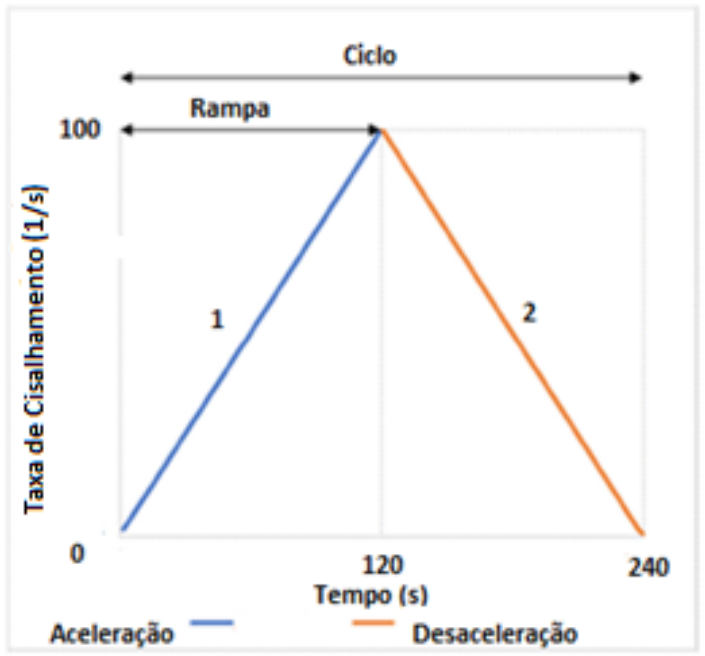

Figura 9: Representação gráfica da evolução da taxa de cisalhamento imposta sobre as pastas de cimento no reômetro.

Este método foi escolhido por ser o mesmo utilizado nos trabalhos de WANG Q. et al. [15], RAUCCI et al. [16], SOARES [17], JIANG et al. [24], BETIOLIi et al. [25], SENFF et al. [26] e SATO et al. [27]. Variando-se a taxa e a tensão de cisalhamento no reômetro, a curva de fluxo é traçada, e a partir de modelos matemáticos apropriados, as propriedades reológicas são determinadas. A curva de fluxo que mais se assemelha ao comportamento médio das cinco réplicas analisadas é então selecionada como resultado. $\mathrm{O}$ objetivo deste ensaio é verificar se a adição de OG altera o comportamento reológico da pasta de cimento no estado fresco, em termos do limite de escoamento e viscosidade plástica.

Os resultados obtidos no reômetro são muito mais precisos do que aqueles obtidos no ensaio de minislump. Isso ocorre, pois a reometria rotacional de fluxo consiste em um ensaio multiponto, aplicável para várias condições de cisalhamento e capaz de produzir um relatório de resultados mais completo, sendo o mais indicado para pesquisa científica e controle de qualidade, segundo RAUCCI et al. [16].

A Figura 10 apresenta uma típica curva de fluxo de uma pasta de cimento, obtida por meio do ensaio de reometria rotacional de fluxo (reômetro).

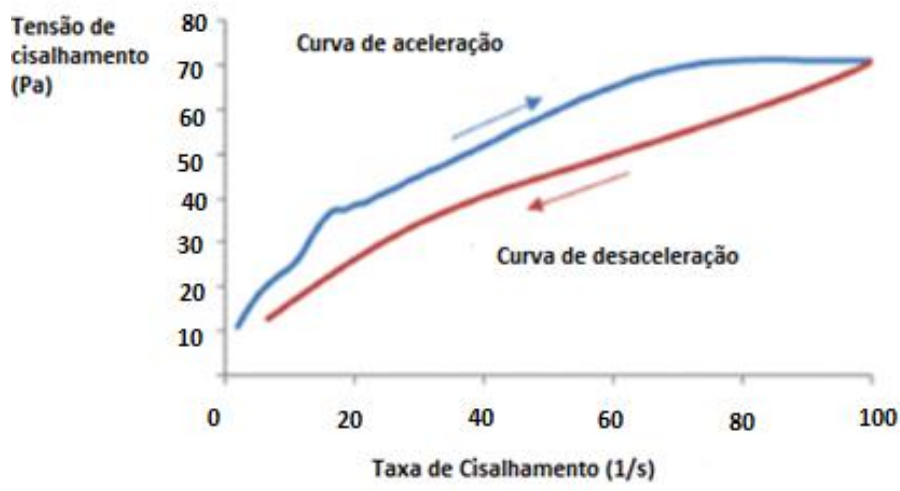

Figura 10: Curva de fluxo de uma pasta de cimento no estado fresco (tensão de cisalhamento $\mathrm{x}$ taxa de cisalhamento).

Pela Figura 10, pode-se observar que a curva de fluxo de uma pasta de cimento é composta de duas curvas: uma ascendente (de aceleração) em que a taxa de cisalhamento varia de 0 a 100 s-1, e outra descendente (de desaceleração) em que a taxa de cisalhamento varia de 100 a 0 s-1.

O ensaio de fluxo gera uma área de histerese formada pelas curvas de aceleração e desaceleração. 
Essa área indica uma quebra microestrutural (micro ligações já formadas) no compósito sob a ação do cisalhamento aplicado. Este fenômeno promove uma redução da tensão de cisalhamento sob a mesma taxa de cisalhamento, em outras palavras, os parâmetros reológicos diminuem com a manutenção da taxa aplicada ao longo do tempo. Os valores mais baixos da tensão de cisalhamento na curva de desaceleração (curva descendente) em relação à curva de aceleração (curva ascendente) indicam um comportamento tixotrópico dos materiais cimentícios, que é a mudança da consistência gelatinosa para uma consistência mais fluida à medida que a pasta é colocada em movimento (RAUCCI et al. [16], SOARES [17], KANTRO [20] e JIANG et al. [24]).

Neste trabalho, os dados para o ensaio de reometria rotacional de fluxo foram calculados a partir da curva de desaceleração, devido a dois motivos principais: i) os valores da tensão de cisalhamento necessária ao escoamento da pasta são mais precisos devido à homogeneização da amostra; ii) esta curva se adequa melhor ao modelo matemático de Bingham (equação 1) expresso a seguir:

$$
\tau=\tau_{0}+\mu \dot{\gamma}
$$

$\tau=$ tensão de cisalhamento $(\mathrm{Pa}) ; \tau_{0}=$ tensão ou limite de escoamento $(\mathrm{Pa}) ; \mu=$ viscosidade plástica $(\mathrm{Pa} . \mathrm{s}) ; \dot{\gamma}=$ taxa de cisalhamento $\left(s^{-1}\right)$.

\section{RESULTADOS E DISCUSSÃO}

\subsection{Mini-slump}

Por meio do ensaio de mini-slump foram obtidos os raios médios de espalhamento das amostras, os quais são apresentados na Tabela 3. Os cálculos referentes à média e desvio padrão das amostras foram realizados com base em 3 corpos de prova.

Tabela 3: Resultados do ensaio de mini-slump.

\begin{tabular}{ccccccc}
\hline \multirow{2}{*}{ Pastas de cimento } & \multicolumn{2}{c}{ REF $^{\mathbf{c}}$} & \multicolumn{2}{c}{ 0,03\%OG } & \multicolumn{2}{c}{ 0,05\%OG } \\
\cline { 2 - 6 } & CP-III & CP-V & CP-III & CP-V & CP-III & CP-V \\
\hline $\begin{array}{c}\text { Raio médio de } \\
\text { espalhamento (mm) }\end{array}$ & 44,92 & 29,63 & 35,54 & 24,46 & 25,63 & 22,71 \\
\hline Desvio padrão (mm) & 0,95 & 2,08 & 3,05 & 1,38 & 0,50 & 0,92 \\
\hline $\begin{array}{l}\text { Coeficiente de variação (\%) } \\
1\end{array}$ & 2,11 & 7,02 & 8,57 & 5,65 & 1,95 & 4,05 \\
\hline $\begin{array}{c}\text { Variação em relação à } \\
\text { REF (\%) }\end{array}$ & NA ${ }^{2}$ & NA & $-20,87$ & $-17,43$ & $-42,94$ & $-23,34$ \\
\hline
\end{tabular}

\footnotetext{
${ }^{1}$ REF: pasta de cimento de referência. ${ }^{2}$ NA: não se aplica.
}

Como se pode observar, as pastas de cimento com adição de $0,03 \%$ OG apresentaram reduções no raio de espalhamento de $20,87 \%$ (CP-III) e de $17,43 \%$ (CP-V) em relação às pastas de referência. Para um teor de adição de $0,05 \% \mathrm{OG}$, as reduções no raio de espalhamento foram de 42,94\% (CP-III) e de 23,34\% (CP-V).

Vale destacar que, durante a realização do ensaio, ocorrem efeitos de interação entre a placa de vidro e a pasta de cimento, restringindo portanto o escoamento da pasta, razão pela qual as reduções no raio de espalhamento obtidas neste trabalho são bastante elevadas. Apesar de não ser normatizado, o ensaio de minislump é bastante útil principalmente em canteiros de obras, diante da inviabilidade de execução de outras técnicas de ensaio mais sofisticadas. A finalidade de utilização deste ensaio é, portanto, o de comparação dos resultados obtidos no mini-slump com os resultados obtidos por meio do reômetro em laboratório.

As reduções observadas na fluidez da pasta à medida que se adiciona o OG se devem a três fatores principais: i) os nanomateriais possuem a tendência de reaglomerar, devido às interações de van der Waals existentes entre as moléculas, sendo que, quando ocorre com maior intensidade, resulta na menor fluidez dos materiais cimentícios (JIANG et al. [24]); ii) o óxido de grafeno é um nanomaterial em escala bidimensional com elevada superfície específica. Ao ser adicionado às pastas de cimento, causa uma elevação na demanda de água necessária para molhar a sua superfície, reduzindo assim o conteúdo de água disponível para a lubrificação (WANG, Q et al. [28]); iii) ao se contabilizar a água da solução de OG no traço das pastas de cimento, o volume da água de mistura deve ser reduzido, de forma a manter fixa a relação água/cimento. 
Com isso, há uma redução evidente no conteúdo de água disponível para envolver os grãos de cimento, tornando a pasta mais viscosa.

As pastas preparadas com cimento $\mathrm{CP}-\mathrm{V}$ apresentam menor fluidez do que as pastas preparadas com cimento CP-III. Isto se deve à maior finura Blaine do cimento CP-V (conforme mostrado anteriormente na Tabela 1) e ao fato deste ser um cimento puro (sem adições), características que tornam este cimento mais reativo (MEHTA e MONTEIRO [29]). Em função disto, em contato com a água, o CP-V inicia suas reações mais rapidamente, fazendo com que a pasta preparada com este cimento se torne mais viscosa do que a pasta de cimento CP-III.

$\mathrm{Na}$ literatura, vários autores relataram reduções significativas na fluidez dos compósitos de cimento com adição de OG em relação às amostras de referência (LV et al. [2], PAN et al. [4], GONG et al. [10], SHANG et al. [11], WANG Q. et al. [30], ZHAO et al. [31] e ZHAO et al. [32]).

De acordo com os estudos realizados por LV et al. [2] e GONG et al. [10], para um teor de adição de $0,03 \%$ de OG sobre pastas de cimento, as reduções no diâmetro médio de espalhamento foram, pelo método do mini-slump, de cerca de $44 \%$ e $35 \%$, respectivamente. De acordo com PAN et al. [4] a presença de $0,05 \%$ de OG aumenta a área superficial em $237 \%$, fato que justifica a redução da plasticidade. Por meio do ensaio de mini-slump, a presença de $0,05 \%$ de OG impactou na redução da fluidez de pastas de cimento em cerca de $42 \%$.

Os autores SHANG et al. [11] e WANG Q. et al. [30] obtiveram reduções de cerca de $27 \%$ e $70 \%$ na fluidez, respectivamente, considerando a adição de $0,05 \%$ de OG sobre pastas de cimento. Os autores ZHAO et al. [31] e ZHAO et al. [32] obtiveram, para argamassas com um teor de adição de 0,022\% de OG, reduções na fluidez de cerca de $14 \%$ e $18 \%$, respectivamente.

Verifica-se que as reduções no raio médio de espalhamento das pastas de cimento devido à adição do OG obtidas neste trabalho são inferiores aos resultados obtidos por LV et al. [2], GONG et al. [10] e WANG Q. et al. [30]. Essa divergência de resultado se deve às diferenças nas características físicas e químicas dos óxidos de grafeno utilizados na literatura. Como o método de produção do OG apresenta bastantes peculiaridades, variando conforme a patente de produção, o produto final também apresenta uma variação intrínseca em suas propriedades, influenciando diretamente na reologia das pastas. Além disso, os autores citados realizaram a ultrassonificação da solução de OG e/ou utilizaram aditivos plastificantes, o que pode ter implicado em diferenças no grau de dispersão do OG no interior da pasta, procedimentos não realizados neste trabalho.

\subsection{Reometria rotacional de fluxo (reômetro)}

Por meio da técnica da reometria rotacional de fluxo foram obtidas as curvas mais representativas de fluxo das pastas de cimento analisadas, as quais são apresentadas nas Figuras 11 e 12.

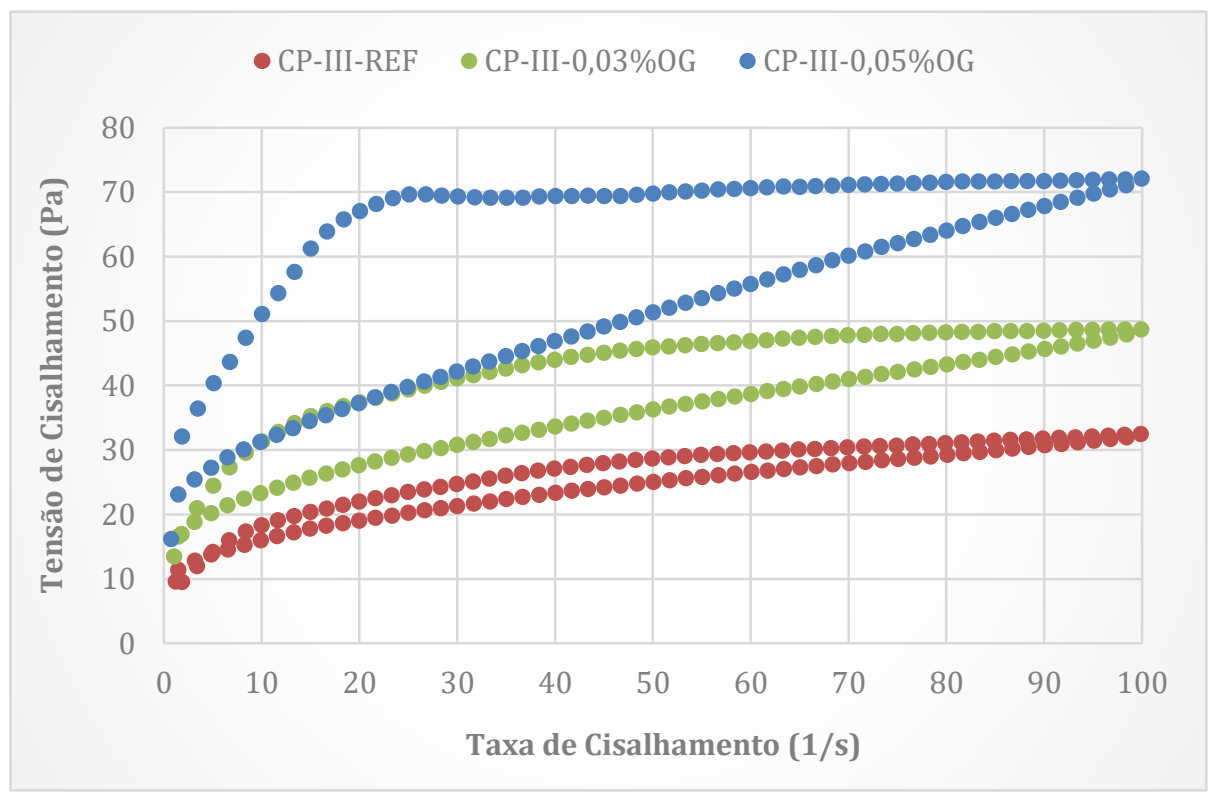

Figura 11: Curvas de fluxo mais representativas do CP-III. 


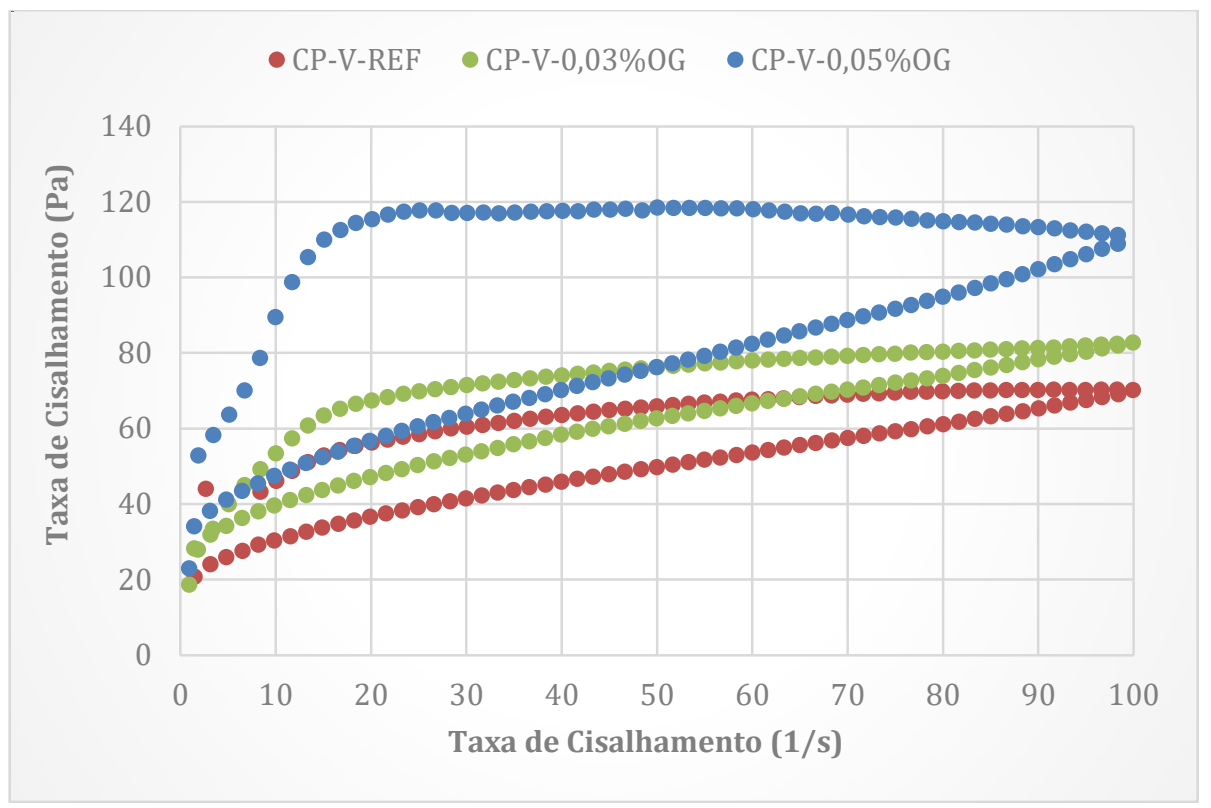

Figura 12: Curvas de fluxo mais representativas do CP-V.

Pelas Figura 11 e 12, pode-se perceber que houve um aumento da área contida no interior das curvas ascendente e descendente de fluxo, conforme aumenta-se o teor de adição de OG. Isto significa que a tixotropia das pastas de cimento (mudança da consistência gelatinosa para uma consistência mais fluida devido ao movimento de rotação) aumentou com a incorporação do OG.

A elevação considerável na tixotropia da pasta ao se adicionar 0,05\% OG é um indicativo de que este teor de adição do OG altera significativamente o comportamento reológico das pastas de cimento. O uso de aditivos plastificantes para teores de OG iguais ou superiores a $0,05 \%$ pode auxiliar na contenção destas mudanças na reologia das pastas, o que explica o fato da maioria dos autores identificados na literatura terem feito o uso deste tipo de aditivo.

A partir dos gráficos retratados nas Figura 11 e 12, realizou-se a seleção das curvas descendentes de fluxo, pelo fato destas curvas apresentarem uma maior tendência de linearização. Por fim, optou-se pela utilização do modelo de Bingham (equação 1) para equacionar o comportamento das curvas de fluxo resultantes, pelo fato destas curvas apresentarem o comportamento aproximado de uma reta de primeiro grau. As Figuras 13 e 14 apresentam o resultado desse processo de tratamento dos dados.

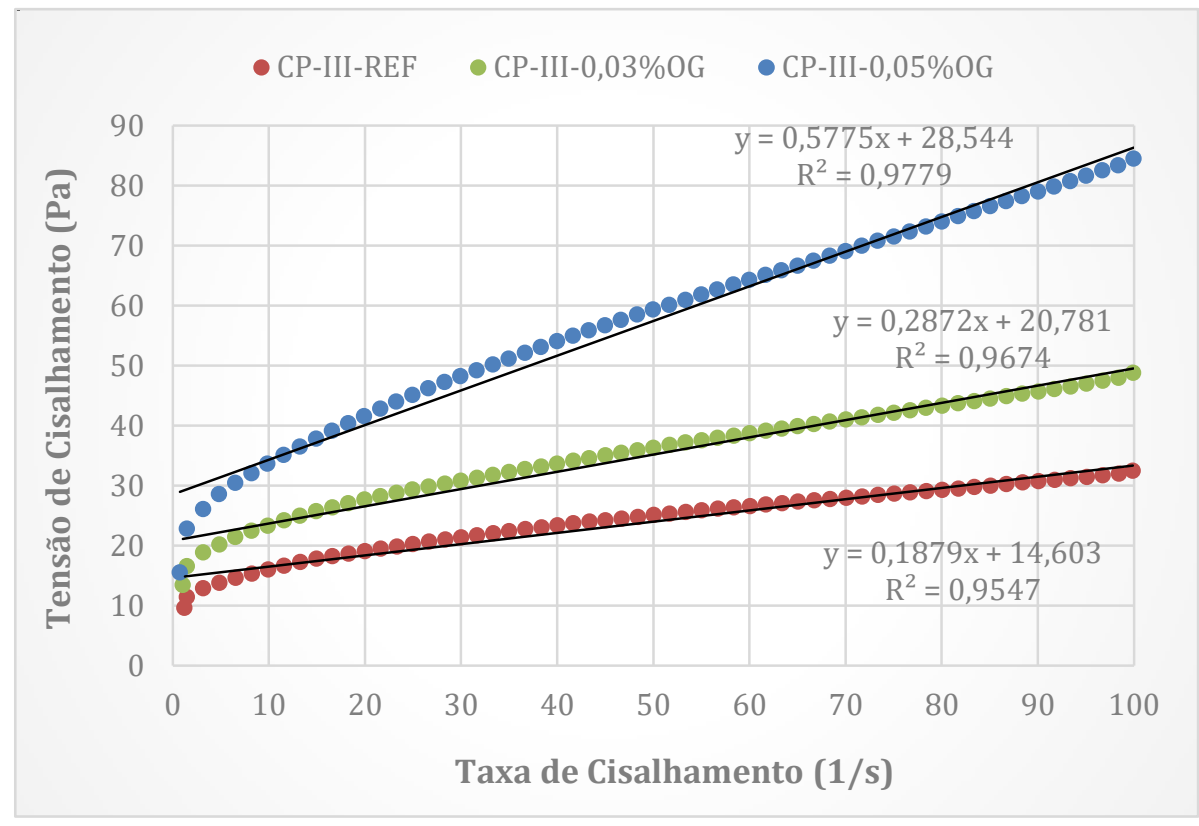

Figura 13: Curvas descendentes de fluxo mais representativas das pastas produzidas com cimento CP-III. 


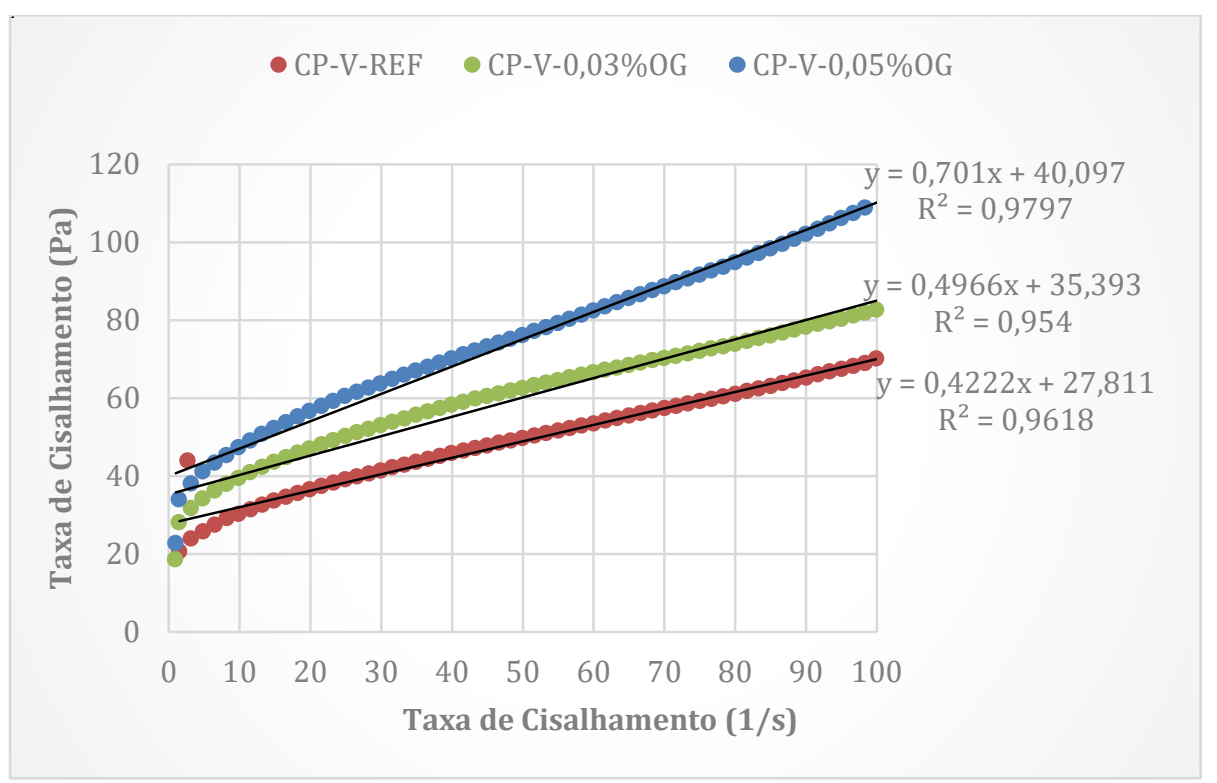

Figura 14: Curvas descendentes de fluxo mais representativas das pastas produzidas com cimento CP-V.

As equações contidas nas Figuras 13 e 14 evidenciam a adequabilidade do modelo de Bingham modificado para as curvas de fluxo dos materiais cimentícios, uma vez que o índice de regressão linear é bem próximo de 1,0 em todos os cenários analisados.

À medida que se aumenta o teor de adição de OG, as curvas de fluxo tendem a apresentar um maior grau de inclinação e são deslocadas para cima, o que, em termos da reologia, representa os aumentos na viscosidade e limite de escoamento, respectivamente.

Por meio de análise gráfica, foram obtidos os parâmetros de viscosidade plástica (Tabela 4) e limite de escoamento (Tabela 5) das pastas de cimento.

Tabela 4: Viscosidade plástica $(\mu)$ e dados estatísticos correspondentes, referentes às curvas de fluxo ajustadas pelo modelo de Bingham modificado.

\begin{tabular}{ccccccc}
\hline & \multicolumn{3}{c}{ REF $^{*}$} & \multicolumn{2}{c}{$\mathbf{0 , 0 3 \% \text { OG }}$} & \multicolumn{2}{c}{ 0,05\%OG } \\
\cline { 2 - 6 } Pastas de cimento & CP-III & CP-V & CP-III & CP-V & CP-III & CP-V \\
\hline $\begin{array}{c}\text { Viscosidade plástica - } \\
\mu \text { (Pa.s) }\end{array}$ & 0,17 & 0,49 & 0,27 & 0,51 & 0,38 & 0,64 \\
\hline \begin{tabular}{c} 
Desvio padrão \\
\cline { 2 - 6 }
\end{tabular} & 0,01 & 0,07 & 0,02 & 0,06 & 0,06 & 0,06 \\
\hline $\begin{array}{c}\text { Coeficiente de } \\
\text { variação (\%) }\end{array}$ & 5,88 & 13,99 & 8,45 & 11,76 & 15,06 & 9,38 \\
\hline $\begin{array}{c}\text { Variação em relação à } \\
\text { REF (\%) }\end{array}$ & $\mathrm{NA}^{2}$ & NA & 60,78 & 4,70 & 125,49 & 31,51 \\
\hline REF pasta de cim
\end{tabular}

${ }^{1}$ REF: pasta de cimento de referência. ${ }^{2}$ NA: não se aplica. 
Tabela 5: Limite de escoamento $\left(\tau_{0}\right)$ e dados estatísticos correspondentes, referentes às curvas de fluxo ajustadas pelo modelo de Bingham modificado.

\begin{tabular}{ccccccc}
\hline \multirow{2}{*}{ Pastas de cimento } & \multicolumn{2}{c}{ REF $^{\mathbf{2}}$} & \multicolumn{2}{c}{ 0,03\%OG } & \multicolumn{2}{c}{ 0,05\% OG } \\
\cline { 2 - 6 } & CP-III & CP-V & CP-III & CP-V & CP-III & CP-V \\
\hline $\begin{array}{c}\text { Limite de escoamento } \\
-\tau_{0}(\mathrm{~Pa})\end{array}$ & 15,62 & 28,76 & 23,39 & 37,16 & 28,47 & 39,94 \\
\hline $\begin{array}{c}\text { Desvio padrão } \\
\text { Coeficiente de } \\
\text { variação (\%) }\end{array}$ & 0,89 & 2,51 & 0,94 & 1,59 & 3,65 & 3,71 \\
\hline $\begin{array}{c}\text { Variação em relação à } \\
\text { REF (\%) }\end{array}$ & 5,72 & 8,74 & 4,01 & 4,29 & 12,82 & 9,28 \\
\hline NEF: & NA $^{2}$ & NA & 49,77 & 29,20 & 82,24 & 38,87 \\
\hline
\end{tabular}

${ }^{1}$ REF: pasta de cimento de referência. ${ }^{2}$ NA: não se aplica.

Nas Tabelas 3, 4 e 5 foi determinado o coeficiente de variação das amostras, ferramenta estatística utilizada para avaliar o grau de dispersão dos resultados em relação à média amostral. Verifica-se que o maior coeficiente de variação encontrado foi de $15,06 \%$, o que indica que os resultados obtidos apresentam precisão e confiabilidade em níveis satisfatórios.

As diferenças no comportamento reológico das pastas estão associadas tanto à finura quanto à composição do cimento. Como a finura Blaine do CP-V é maior e este é caracterizado como um cimento puro (sem adições), a sua reatividade é consideravelmente maior (MEHTA e MONTEIRO [29]). Em função disto, em contato com a água, o CP-V inicia suas reações mais rapidamente, fazendo com que a pasta de cimento de referência apresente viscosidade e limite de escoamento superiores em $288 \%$ e $184 \%$, respectivamente, em relação à pasta de cimento $\mathrm{CP}$-III de referência. Pelo fato da pasta de cimento $\mathrm{CP}-\mathrm{V}$ de referência já apresentar constantes reológicas elevadas, a adição do OG não produz um efeito tão significativo como aquele observado em pastas de cimento CP-III. Este fato é evidenciado pelo menor distanciamento entre as curvas de fluxo no caso do $\mathrm{CP}-\mathrm{V}$, comparativamente às curvas de fluxo do $\mathrm{CP}$-III, conforme mostrado nas Figuras 11 a 14. Com base nisto, pode-se inferir que as pastas de cimento CP-III são mais sensíveis às alterações em seu comportamento reológico provocadas pela adição do OG.

SHANG et al. [11] identificaram aumentos de cerca de $190 \%$ na viscosidade e de $240 \%$ no limite de escoamento de pastas de cimento com adição de $0,05 \%$ de $\mathrm{OG}$ em relação à amostra de referência. Também considerando uma adição de 0,05\% OG, os autores WANG Q. et al. [28] obtiveram aumentos de cerca de $420 \%$ na viscosidade e de $1030 \%$ no limite de escoamento, enquanto que WANG Q. et al. [30] encontraram aumentos de cerca de $1950 \%$ na viscosidade. Essa divergência de resultado se deve às diferenças nas características físicas e químicas dos óxidos de grafeno utilizados na literatura. Como o método de produção do OG apresenta bastantes peculiaridades, variando conforme a patente de produção, o produto final também apresenta uma variação intrínseca em suas propriedades, influenciando diretamente na reologia das pastas. Além disso, os autores citados realizaram a ultrassonificação da solução de OG e/ou utilizaram aditivos plastificantes, o que pode ter implicado em diferenças no grau de dispersão do OG no interior da pasta, procedimentos não realizados neste trabalho.

\section{CONCLUSÃO}

Neste trabalho de pesquisa foram investigadas as alterações no comportamento reológico de pastas de cimento devido à adição de OG. Foram utilizados para isso dois métodos de análise, o mini-slump e a reometria rotacional de fluxo.

Mesmo para teores tão baixos de adição do OG (0,03\% e 0,05\%), ficou evidente a alteração no comportamento reológico dos materiais cimentícios. No ensaio de mini-slump, foram obtidas reduções no raio de espalhamento de 20,88\% (0,03\%OG) e de 42,94\% (0,05\%OG). Já no ensaio de reometria rotacional de fluxo, foram obtidos aumentos na viscosidade plástica de 60,78\% (0,03\%OG) e 125,49\% (0,05\%OG), e no limite de escoamento de 49,77\% (0,03\%OG) e 82,24\% (0,05\%OG). Ainda que as alterações no comportamento reológico das pastas tenham sido maiores para o teor de adição de $0,05 \% \mathrm{OG}$, foi possível a moldagem de corpos de prova sem a utilização de aditivos plastificantes.

Os resultados encontrados atenderam aos objetivos propostos nesta pesquisa. Tanto a técnica de minislump quanto a reometria rotacional de fluxo se mostraram eficientes na determinação da influência da adição da solução de OG sobre o comportamento reológico das pastas de cimento. Ambas as técnicas apontaram para o aumento da viscosidade plástica e redução da fluidez da pasta à medida que uma maior quantidade de $\mathrm{OG}$ é incorporada à mistura. A diferença principal entre as técnicas está na forma dos resultados obtidos. A reometria rotacional de fluxo é um método mais sofisticado e produz um relatório de 
resultados mais completo e preciso, gerando a curva de fluxo das amostras para várias condições de cisalhamento (ensaio multiponto). Já a técnica de mini-slump é um método de ensaio mais prático e com menor grau de precisão, porém possui como vantagem permitir a visualização dos efeitos das adições sobre a fluidez e a consistência das pastas de cimento, ainda que para um único par de valores de tensão e taxa de cisalhamento aplicados (ensaio monoponto). As técnicas de reologia empregadas são, portanto, complementares, e buscam explicar as alterações no comportamento dos materiais no estado fluido devido às adições.

\section{AGRADECIMENTOS}

Os autores agradecem a CAPES, o Centro Federal de Educação Tecnológica de Minas Gerais (CEFET-MG) e o Centro de Tecnologia em Nanomateriais e Grafeno da Universidade Federal de Minas Gerais (CTNano/UFMG) pelo apoio financeiro e técnico fornecido para o desenvolvimento deste trabalho de pesquisa.

\section{BIBLIOGRAFIA}

[1] YANG, H., et al. Composites: Part A, A critical review on research progress of graphene/cement based composites, Composites Part A, v. 102, pp. 273-296, 2017.

[2] LV, S., et al, Fabrication of polycarboxylate/graphene oxide nanosheet composites by copolymerization for reinforcing and toughening cement composites, Cement and Concrete Composites, v. 66, pp. 1-9, fev. 2016.

[3] LU, C., et al, Effect of graphene oxide on the mechanical behavior of strain hardening cementitious composites, Construction and Building Materials, v. 120, pp. 457-464, set. 2016.

[4] PAN, Z., et al., Mechanical properties and microstructure of a graphene oxide - cement composite, Cement and Concrete Composites. v. 58, pp. 140-147, 2015.

[5] MOHAMMED, A., et al., Incorporating graphene oxide in cement composites: A study of transport properties, Construction and Building Materials, v. 84, pp. 341-347, jun. 2015.

[6] LU, C., et al, Effect of graphene oxide on the mechanical behavior of strain hardening cementitious composites, Construction and Building Materials, v. 120, pp. 457-464, set. 2016.

[7] LIN, C., WEI, W., HU, Y.H., Catalytic behavior of graphene oxide for cement hydration process, Journal of Physics and Chemistry of Solids, v. 89, pp. 128-133, fev. 2016.

[8] HOU, D., et al, Reactive molecular dynamics and experimental study of graphene-cement composites: Structure, dynamics and reinforcement mechanisms, Carbon, v. 115, pp. 188-208, 1 maio 2017.

[9] ZHAO, L., et al., Mechanical behavior and toughening mechanism of polycarboxylate superplasticizer modified graphene oxide reinforced cement composites, Composites Part B: Engineering, v. 113, pp. 308316, mar. 2017.

[10] GONG, K., PAN, Z., et al., Reinforcing effects of graphene oxide on portland cement paste, Journal of Materials in Civil Engineering, v. 27, n. 2, fev. 2015.

[11] SHANG, Y., et al., Effect of graphene oxide on the rheological properties of cement pastes, Construction and Building Materials, v. 96, pp. 20-28, out. 2015.

[12] ABNT - Associação Brasileira de Normas Técnicas. NBR 16697:2018 - Cimento Portland - Requisitos. Rio de Janeiro, 2018.

[13] LV, S., et al., Effect of graphene oxide nanosheets of microstructure and mechanical properties of cement composites, Construction and Building Materials, v. 49, pp. 121-127, 2013.

[14] WANG, M., et al., Study on the three dimensional mechanism of graphene oxide nanosheets modified cement, Construction and Building Materials, v. 126, pp. 730-739, 15 nov. 2016.

[15] WANG, Q., et al., Rheological behavior of fresh cement pastes with a graphene oxide additive, Xinxing Tan Cailiao, New Carbon Materials, v. 31, n. 6, pp. 574-584, 2016.

[16] RAUCCI, J.S., et al., Effect of mixing method on the mini-slump spread of Portland cement pastes, Revista IBRACON de Estruturas e Materiais, v. 11, n. 2, pp. 410-431, 2018.

[17] SOARES, P.A., “Caracterização da reologia no estado fresco de pastas de cimento Portland fabricadas com nanotubos de carbono sintetizados diretamente sobre o clínquer”, Tese de M.Sc., Universidade Federal de Minas Gerais. Belo Horizonte, MG, Brasil, 2019.

[18] PROCELAB, Procedimentos e Métodos de Laboratório destinados à Cimentação de Poços Petrolíferos. Petrobras, 2005. 
[19] MAKAR, J.M., CHAN, G.W., Growth of cement hydration products on single-walled carbon nanotubes, Journal of the American Ceramic Society, v. 92, n. 6, pp. 1303-1310, 2009.

[20] KANTRO, D.L., Influence of Water-Reducing Admixtures on Properties of Cement Paste - A Miniature Slump Test, Cement, Concrete, and Aggregates, v. 2, n. 2, pp. 95-102, 1980.

[21] PASHIAS, et al., A fifty cent rheometer for yield stress measurement, Journal of Rheology, v. 40, n. 6, pp. 1179-1189, 1996.

[22] CASTRO, A.L., LIBORIO, J.A importância da avaliação reológica de pastas com e sem sílica ativa para produção de concretos estruturais com cimento Portland para obras marítimas, Disponível em: <http://www.semengo.furg.br/2004/02_2004.pdf>.

[23] ROUSSEL, N., STEFANI, C., LEROY, R., From mini-cone test to Abrams cone test : measurement of cement-based materials yield stress using slump tests, Cement and Concrete Research, v. 35, pp. 817-822, 2005 .

[24] JIANG, S., et al., Rheological properties of cementitious composites with nano/fiber fillers, Construction and Building Materials, v. 158, pp. 786-800, 2018.

[25] BETIOLI, A. M. et al., Caracterização reológica de pasta cimentícia: associação de técnicas complementares, Associação Nacional de Tecnologia do Ambiente Construído, v. 9, n. 4, pp. 37-48, 2009.

[26] SENFF, L., HOTZAII, D., REPETTEIII, W., Comportamento reológico de pastas de cimento com adição de sílica ativa, nanossílica e dispersante policarboxílico, Revista Matéria, v. 15, n. 1, pp. 12-20, 2010.

[27] SATO, V. Y. et al., “Aplicação dos Conceitos de Reologia no Estudo de Pastas Cimentícias”, In: Anais do $55^{\circ}$ Congresso Brasileiro do Concreto, Gramado, RS, Brasil, n. 1, p. 1-14, out. 2013.

[28] WANG, Qin et al., Rheological behavior of fresh cement pastes with a graphene oxide additive, New Carbon Materials, v. 31, n. 6, pp. 574-584, dez. 2016.

[29] MEHTA, P.K; MONTEIRO, P.J.M. ,Concreto: microestrutura, propriedades $e$ materiais, $3^{\mathrm{a}}$ ed, São Paulo, Ibracon, 2008.

[30] WANG, Q., et al., Influence of graphene oxide additions on the microstructure and mechanical strength of cement, New Carbon Materials, v. 30, n. 4, pp. 349-356, ago. 2015.

[31] ZHAO, L., et al., Mechanical behavior and toughening mechanism of polycarboxylate superplasticizer modified graphene oxide reinforced cement composites, Composites Part B: Engineering, v. 113, pp. 308316, 2017.

[32] ZHAO, L., et al., Investigation of the effectiveness of PC@ GO on the reinforcement for cement composites, Construction and Building Materials, v. 113, pp. 470-478, 2016.

\section{ORCID}

Ricardo Augusto dos Santos Horta

Júnia Nunes de Paula

José Márcio Fonseca Calixto

Júlia Fonseca Murta https://orcid.org/0000-0002-2552-0972

https://orcid.org/0000-0002-8522-2627

https://orcid.org/0000-0003-2828-0967

https://orcid.org/0000-0002-8337-0562 